\title{
CONEXÕES ENTRE ASSOCIACCÕES NACIONAIS, PROCESSOS FORMATIVOS E POLIITICAS EDUUCACIONAIS PARA O ENSINO DA ARTE: CARTOGRAFIAS DE UMA LUTA
}

\author{
Ana Paula Abrahamian de Souza \\ Universidade Federal Rural de Pernambuco (UFRPE) \\ Fabiana Souto Lima Vidal \\ Universidade Federal de Pernambuco (UFPE)
}

\section{RESUMO}

Este texto é produto das reflexões advindas do XXVIII CONFAEB - Congresso Nacional da Federação de Arte/Educadores do Brasil e do VI Congresso Internacional de Arte-Educação, promovido pela Federação de Arte-Educadores do Brasil no ano de 2018, em Brasília, que contou com uma mesa temática sobre o trabalho que tem sido empreendido conjuntamente pelas Associações de Ensino e de Pesquisa em Arte, no campo da formação de docentes e no debate acerca das políticas públicas educacionais para o ensino e a pesquisa no campo da Arte no Brasil. Nos limites deste artigo, partilharemos uma cartografia das ações faebianas e seu diálogo com as demais associações nos últimos anos, na tentativa de fortalecer do debate sobre a ampliação de ações para o redimensionamento de políticas públicas educacionais que tratam o campo epistêmico da Arte/Educação em suas diferentes linguagens - Artes Visuais, Dança, Música e Teatro - de forma compromissada com os processos artísticos, éticos e estéticos de ensinar e de aprender Arte em diferentes processos educativos.

Palavras-chave: Arte/Educação. Associações nacionais. Políticas públicas educacionais. Processos formativos. FAEB. 


\section{Introdução}

Não estamos sós. Não somos sós. Somos seres coletivos. Estamos sempre embrenhados em uma teia de alteridade que nos envolve e nos move. Nossa essência é uma coletividade de forças - materiais, sociais, invisíveis - em permanente rearranjo. (Pereira, 2013, p. 187).

$\Delta$ o longo de seus 30 anos de existência, a Federação de Arte/Educadores do Brasil (FAEB) tem se constituído como um espaço de enfrentamentos, diálogos e produções no campo da Arte/Educação, compartilhando os debates e lutas em prol das políticas públicas na Educação e na Cultura com algumas associações: a Associação Nacional de Pesquisa em Artes Plásticas (ANPAP), a Associação Nacional de Pesquisadores em Dança (ANDA), a Associação Brasileira de Educação Musical (ABEM), a Associação Brasileira de Pesquisa e Pós-graduação em Artes Cênicas (ABRACE), a Associação Nacional de Pesquisa e Pós-Graduação em Música (ANPPOM), a Rede de Educadores em Museus (REMs), entre outras instâncias, provocando um exercício de contaminação de um chão comum para as relações do ensinar e do aprender arte.

Tais ações foram intensificadas entre 2014 e 2018, anos marcados pelos debates em torno do documento preliminar da Base Nacional Comum Curricular (BNCC), proposta pela Secretaria de Educação Básica do Ministério da Educação (SEB/MEC); pelos debates em torno do Programa Nacional de Bolsas de Iniciação à Docência (PIBID), da Reforma do Ensino Médio, da formulação das Diretrizes Nacionais Curriculares para a Formação do Magistério da Educação Básica, além da alteração, no ano de 2016, da Lei de Diretrizes e Bases da Educação Nacional n 9.394, de 20 de dezembro de 1996.

Atualmente estamos engajados(as) no debate sobre o futuro das políticas públicas no campo da Arte e do seu ensino nos diferentes espaços para que as Artes Visuais, a Dança, a Música e o Teatro, sejam tratadas como componentes curriculares específicos que compõem o campo da Arte, portanto, com modos de ensinar e aprender diferenciados e que não podem ser vistos pelo viés da polivalência, entendimento que ainda persiste no campo das práticas escolarizadas e não escolarizadas e na produção de políticas curriculares.

$O$ presente artigo é fruto de mais um encontro realizado no XXVIII Congresso Nacional da Federação de Arte/Educadores do Brasil, em Brasília, que mobilizou as Associações de Ensino e de Pesquisa em Arte para ampliação dos debates acerca das políticas públicas educacionais para o ensino e para a pesquisa no campo da Arte no Brasil. Partimos da memória da FAEB, que vem liderando lutas em favor da obrigatoriedade da arte na educação formal, bem como sua presença nos processos informais e não formais de ensino e de aprendizagem, mobilizando arte/educa- 
dores(as) da área das Artes Visuais, da Dança, da Música e do Teatro em diferentes frentes de trabalho.

Para a composição deste texto, foram utilizados boletins, notas de repúdio, manifestos, cartas, ofícios e demais documentos produzidos pela FAEB ao longo do período, com a finalidade de traçar uma cartografia (Deleuze; Guattari, 1995) da luta nos últimos anos ressaltando a potência da capacidade associativa dos arte/educadores(as) no Brasil, que têm operado traçando "mapas" de corresponsabilidade entre as políticas curriculares educacionais para o ensino da Arte, incidindo sobremaneira nos marcos de luta e de resistência no campo da Arte/Educação no Brasil.

\section{A Federação de Arte/Educadores do Brasil: um pouco de sua história}

Desde a década de 1970, o ensino da Arte tem se constituído "numa questão socialmente problematizada" (Azevedo, 1997). As décadas de 1980 e 1990 foram marcadas por um conjunto de discussões políticas e conceituais sobre o ensino da Arte (Azevedo, 2010; Barbosa, 2005, 2002, 1998; Richter, 2002). A FAEB surge no bojo desse movimento e se vincula a uma agenda de lutas em diferentes planos. Criada em 1987, constituiu-se na primeira entidade civil voltada à pesquisa e ao ensino das áreas artísticas em âmbito nacional, congregando diferentes associações e, mais recentemente, expandindo-se a partir de uma rede de representantes estaduais em todas as regiões do país, com profissionais vinculados(as) às redes de educação municipal, estadual, universidades e institutos federais, além de professores(as), artistas e pesquisadores(as) que atuam em contextos de educação não formal e informal.

O que podemos inferir é que a história das políticas públicas educacionais para o ensino da Arte no Brasil se confunde com a própria história da FAEB, como nos fala a professora Ana Luiza Ruschel Nunes (2018, p. 8):

As políticas públicas e o ensino das artes no país nascem também em encontros, seminários e congressos municipais, estaduais, latino-americanos e internacionais de maior abrangência. Culminaram em diferentes processos já iniciados com a Carta Protesto de Brasília e o documento síntese que foi encaminhado à Comissão de Educação, Cultura e Desportos, e chegaram em 1987 à Constituinte. Em 1988, em Brasília, o I Congresso da FAEB elaborou um documento com uma Moção que foi encaminhada ao V Congresso Brasileiro de Educação (CBE), que, em plenária, aprovou a moção que garantiu o conhecimento da Arte e seu espaço na Educação Básica na então nova LDBN n. 9.394/96/1996, umas das grandes conquistas dos arte/educadores. 
No âmbito das articulações e das relações internacionais, a FAEB representa o Brasil junto ao Conselho Latino-Americano de Educação pela Arte (CLEA), a International Society for Education through Art (InSEA) e também junto à Organização Ibero-americana de Educação pela Arte (OIE). Dialoga, assim, com uma rede de entidades que almeja o fortalecimento da criação artística e o acesso à cultura.

Os cenários de lutas e vigílias sempre foram uma constante na Federação em suas diferentes diretorias, seja dialogando junto a parlamentares, a exemplo da Constituinte de 1988, seja questionando o Conselho Nacional de Educação (CNE) no momento da elaboração das diretrizes para o ensino superior e para a educação básica, entre várias outras frentes.

Durante a Assembleia Constituinte de 1988, os arte-educadores se posicionaram a favor das liberdades democráticas e pelo direito à educação e à cultura. Na década seguinte, o movimento faebiano exerceu pressão sobre o Congresso Nacional durante o processo de discussão da Lei de Diretrizes e Bases da Educação Nacional - LDBEN no 9.394/96, que consolidou a presença da arte como componente curricular obrigatório na educação básica. A FAEB se fez presente na interlocução junto ao Conselho Nacional de Educação (CNE) no momento da elaboração das diretrizes para o ensino superior e para a educação básica. Em 2010, a FAEB reivindicou a inclusão dos conteúdos de arte na matriz do Instituto Nacional de Estudos e Pesquisas Educacionais Anísio Teixeira - INEP - voltada para a seleção de docentes para a educação básica. (FAEB, s.d.).

Um dos marcos de luta da FAEB foi o intermitente trabalho junto às instâncias públicas do Legislativo na tramitação da alteração da Lei de Diretrizes e Bases da Educação Nacional (LDBEN no 9.394/96), que, em seu art. 26, § 2, estabelecia que "O ensino da arte constituirá componente curricular obrigatório, nos diversos níveis da educação básica, de forma a promover o desenvolvimento cultural dos alunos". Como podemos observar, este parágrafo não definia as áreas de conhecimento a serem trabalhadas no currículo. Em 2014, a diretoria vigente da FAEB encaminhou ofício e fez pressão para garantir a alteração do $\S 2^{\circ}$ e $\S 6^{\circ}$ do art. 26 da Lei n० 9.394, de 20 de dezembro de 1996; do Projeto de Lei no 7.032, de 2010, Apenso PL n 4, de 2011, fixando a obrigatoriedade das Artes Visuais, da Dança, da Música e do Teatro nas diretrizes e bases da educação nacional, em substituição ao termo "Arte". Este apenso foi aprovado e sancionado pela então presidenta Dilma Rousseff, em 2 de maio de 2016.

Assim, a Lei no 13.278/16 alterou o referido parágrafo, determinando as Artes Visuais, a Dança, a Música e o Teatro como linguagens obrigatórias que constituem o componente curricular Arte na Educação Básica. Além disso, estabeleceu um prazo de cinco anos para que "os sistemas de ensino implantem as mudanças decorrentes desta Lei, incluída a necessária e adequada formação dos respectivos professores em número suficiente para atuar na educação básica" (Brasil, 2016). 
Uma outra frente de ações que precisamos destacar é o trabalho de mapeamento das produções científicas e dos relatos de experiências dos(as) professores(as), artistas e acadêmicos(as) nos diferentes processos educativos, configurados na produção dos anais dos Congressos Nacionais da Federação (ConFAEBs). Esse mapeamento foi realizado na gestão 2015-2016. Vejamos:

[...] buscou junto a presidentes, ex-presidentes, conselheiros e representantes associados da FAEB, mapeando, catalogando e editando os anais, disponibilizados em 2016 no site da FAEB (www.faeb.com.br). Com aproximadamente mais de 3.000 (três mil) publicações, dentre as quais destacam-se aqui o tema das Políticas Públicas da Educação e o ensino das Artes Visuais, Dança, Música e Teatro, que são recorrentes em relação aos diferentes contextos históricos das mudanças das políticas públicas sociais. (Nunes, 2018, p. 9).

Nos últimos anos, a incidente ameaça pelo governo de dissolução e silenciamento das conquistas adquiridas no campo da Arte/Educação, muitas delas ocorridas por meio de alterações legislativas, decretadas por Medidas Provisórias (MP), tem tentado silenciar a obrigatoriedade do ensino da Arte na educação básica e fez com que a FAEB mobilizasse entidades representativas dos profissionais da Arte e da Arte/Educação.

[...] estes grupos, como frentes para discussões, reinvindicações e criação de ganhos e de trabalhos coletivos, organizaram e formalizaram processos, procedimentos, estratégias e técnicas de difusão, ampliação, defesa, legitimação e construção dos conhecimentos específicos, na articulação e no diálogo com as instâncias de políticas públicas, instituições, organizações e demais entidades de classe, nacionais e internacionais, em ações individualizadas e conjuntas. (Fernandes, 2018, p. 71).

Na próxima seção elencaremos, mesmo que de forma breve, algumas tessituras de ações e provocações realizadas pela FAEB em torno das políticas públicas no campo da Arte, da Educação e da Cultura, e compartilhamento destas ações, juntamente com a ANPAP, a ANDA, a ABEM e a ABRACE, instâncias representativas do campo da Arte.

\section{Ideias disparadoras e ações conjuntas entre as associações de pesquisa e ensino da arte: as "vigílias cívicas" continuam}

Nos últimos anos, a FAEB tem intensificado e compartilhado os debates e lutas em prol das políticas públicas na Educação e na Cultura; para tanto, deu início a um movimento de ações e união das associações e instâncias representativas, dentre 


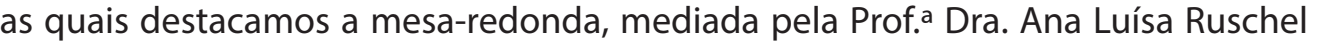
Nunes (UEPG/PR) em 2014, durante o XXIV CONFAEB, ocorrido em Ponta Grossa (PR), e que teve como tema central "Associações de Arte/Educadores do Brasil - Artes Visuais, Dança, Música, Teatro: metamorfoses das políticas públicas, formação e atuação na educação básica".

A referida mesa contou com participação de representações das instâncias, como a Prof.a Dra. Lúcia Gouvêa Pimentel (UFMG/MG), vice-presidente da ANPAP, abordando o tema "Políticas Públicas para o campo do ensino das Arte Visuais na Educação Básica: contribuições e metamorfoses da Associação Nacional dos Pesquisadores em Artes Plásticas (ANPAP)"; com a Prof.a Dra. Márcia Maria Strazzacappa Hernãndes (UNICAMP/SP), coordenadora do GT Educação e Arte da Associação Nacional dos Pesquisadores em Educação (ANPED), com o tema "Formação de Professores de Dança e a Educação Básica: realidades, caminhos e transformações diante das políticas públicas"; o Prof. Dr. Luís Ricardo Silva Queiróz (UFPB/PB), presidente da ABEM, discutiu o tema "Políticas Públicas para o ensino de Música na Educação Básica: conquistas, avanços e perspectivas futuras da Associação Brasileira de Educação Musical (ABEM)"; o Prof. Dr. Narciso Laranjeira Telles da Silva (UFU/MG), presidente da $A B R A C E$, discutiu o tema "O papel da Associação de Pesquisadores em Artes Cênicas (ABRACE): narrativas e metamorfoses diante das políticas públicas", e a Prof. ${ }^{a}$ Dra. Maria das Vitórias Negreiros do Amaral (UFPE/PE), presidente da FAEB, apresentou o tema "FAEB e políticas públicas para a formação de professores das Artes e atuação na Educação Básica: organização, conquistas e avanços dos arte/ educadores do Brasil".

Em síntese, tomamos a contribuição de Pimentel (2014) quando, a partir da instituição que representa e que pode ser estendida para as demais instâncias representativas, considerando as especificidades das linguagens artísticas, propõe a seguinte questão: "Em que medida a ANPAP contribui ou pode contribuir para as políticas públicas no campo do ensino/aprendizagem das Artes Visuais na educação básica?". Ao pensar possíveis respostas, em suas reflexões, a autora se aproxima do movimento que vem sendo tomado pela FAEB, uma vez que sugere que estas contribuições podem acontecer a partir da integração, articulação e apoio das/nas lutas pelas causas comuns (Pimentel, 2014, p. 150).

Vale destacar que, ainda dentro da programação do evento, realizou-se o "I Fórum de coordenadores das Licenciaturas em Artes Visuais, Dança, Música e Teatro/ Artes Cênicas do Brasil", aberto aos(às) coordenadores(as) das universidades, faculdades, institutos e cursos em EaD federais, estaduais, particulares e comunitários.

Em novembro de 2015, comemorando 25 anos, realiza-se em Fortaleza (CE) o XXV CONFAEB com a temática "Políticas públicas e ensino das Artes: formação em Artes Visuais, Dança, Música e Teatro". Dentre os debates importantes em torno da temática, destacamos a conferência dada pela Prof. ${ }^{a}$ Dra. Ana Mae Barbosa, que teve como título "Políticas públicas para o ensino da Arte no Brasil: o perde e ganha das lutas". Na ocasião, a pesquisadora focou na historicidade, com visão crítica sobre 
a compreensão de que políticas públicas podem validar ou silenciar o campo da Arte na Educação e, no caso específico da BNCC, o panorama mercadológico, técnico, acrítico e neoliberal que marca a agenda de trabalho instituída por esta política pública (BARBOSA, 2015).

Os anos de 2015 e 2016 foram significativos para a pauta conjunta de lutas das associações no campo educacional, com a publicação da primeira versão da Base Nacional Comum Curricular (BNCC). Prevista na Lei no 13.005/14, que estabelece o Plano Nacional de Educação (PNE), 2014-2024, a BNCC teve como prazo o mês de junho de 2016 para ser elaborada e encaminhada ao CNE. Sobre a primeira versão desse documento, a FAEB, em seu boletim, nos esclarece:

A primeira versão do documento (proposta preliminar), realizada "a toque de caixa", teve dois tempos de consulta pública na plataforma digital, sendo o segundo tempo (até 15 de março de 2016) concomitante com a reescrita da segunda versão, a partir das sugestões já enviadas de 16 de setembro a 15 de dezembro de 2015; processo fragmentado de contribuições, adequações e ajustes. (FAEB, 2016).

Diante do exposto, não podemos nos furtar de ressaltar que o caráter democrático e a abertura para o debate, pressuposto defendido e amplamente divulgado para a proposição desse documento, de fato não se estabeleceu, e a composição da BNCC, ainda que aberta à consulta pública, não apresentou clareza quanto às contribuições deixadas pelos(as) professores(as).

Ainda segundo o Boletim supracitado, a FAEB debruçou-se sobre o documento da BNCC, no componente Arte, identificando "lacunas, inconsistências, problemas e falhas" que precisavam ser retificados, além das dissonâncias que em nada refletiam as conquistas históricas no campo da Arte/Educação. Os esforços empreendidos voltaram-se para a organização de leituras, análises e discussões sobre as muitas questões envolvidas, particularmente sobre as contradições do componente Arte alocado na área de Linguagens.

Foram muitas as contribuições, amplas as discussões e profundas as análises e reflexões. Das centenas de e-mails trocados pela diretoria e sócios até as tratativas no XXV Confaeb (Congresso da Federação de Arte-Educadores do Brasil), passando pelo grupo fechado do Facebook FAEB/BNCC, inaugurado em 28/09 para fomentar o material para a mesa do Confaeb sobre o tema. $O$ processo subsidiou a visão e mobilizou a FAEB a considerar as limitações da ferramenta de consulta e a solicitar ao Ministério da Educação participação na forma de construção coletiva do texto da BNCC para a Arte na sua versão definitiva. (FAEB, 2016). 
O primeiro documento produzido em conjunto com as associações, o Ofício 06/2015/FAEB, dirigido ao Ministério da Educação, à Secretaria da Educação Básica, à Diretoria de Currículos e Educação Integral, à Comissão Bicameral da BNCC e à equipe de especialistas da área de Arte da BNCC, assinado pela presidenta da FAEB e pelos presidentes das quatro associações de arte e ensino (ABEM, ABRACE, ANDA e ANPAP), observou os princípios das Artes Visuais, da Dança, da Música e do Teatro, repudiou a utilização do termo subcomponente e indicou a área específica de Arte para os quatro componentes serem devidamente considerados na epistemologia das linguagens, como conhecimento e em seus aspectos sociopolíticos, históricos e culturais.

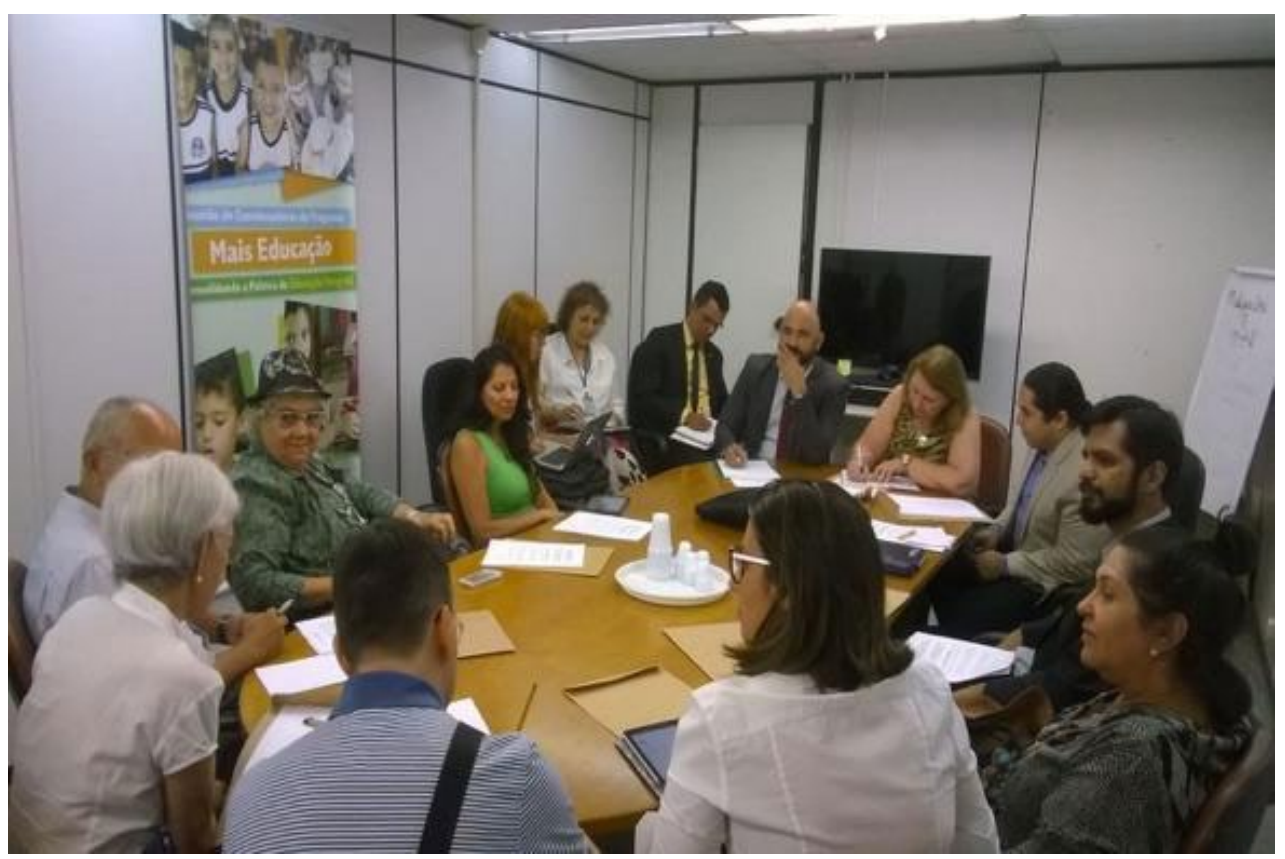

Imagem 1: Primeira reunião no MEC/SEB em 18/2/2016. Fonte: Acervo da FAEB.

Nas tratativas iniciais e na produção do documento conjunto assinado pelas associações, o termo "subcomponente" foi retirado do texto da segunda versão da BNCC.

Essa foi uma primeira vitória diante da primeira versão da BNCC. Portanto, a partir do Ofício 06/2015 e na reunião na SEB/MEC, ao ser indagado pela presidenta da FAEB, o assessor da área da Arte, ao escutar mais uma vez a reivindicação, reconheceu o lapso dos especialistas em colocar o termo subcomponente. [...]. Nessa direção, na segunda versão, aparece não mais a denominação subcomponente, e sim, componente curricular em Artes Visuais, componente curricular em Dança, componente curricular em Música e componente curricular em Teatro. (FAEB, 2016). 


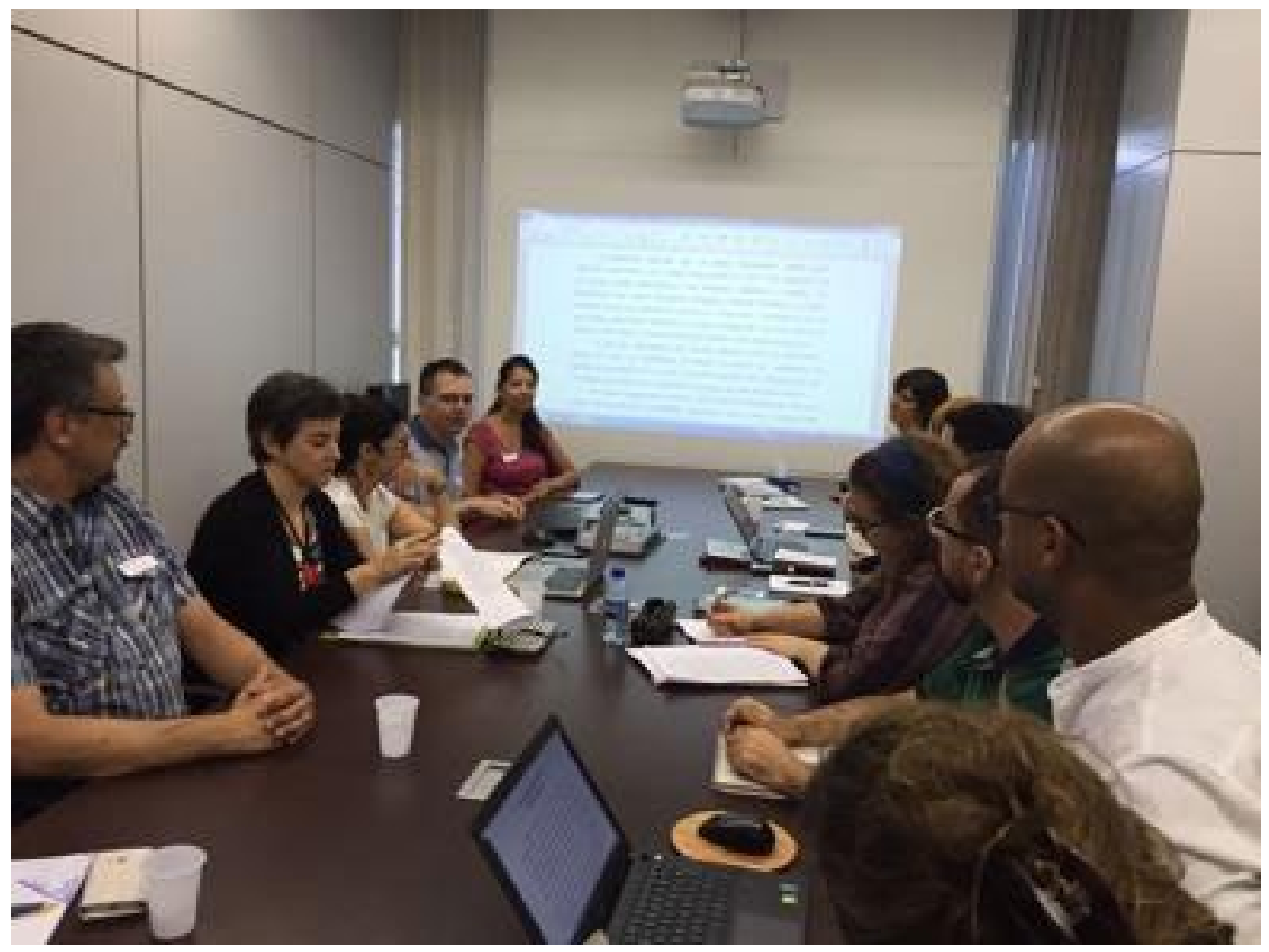

Imagem 2: Registro de reunião no MEC-SEB. Fonte: Acervo FAEB.

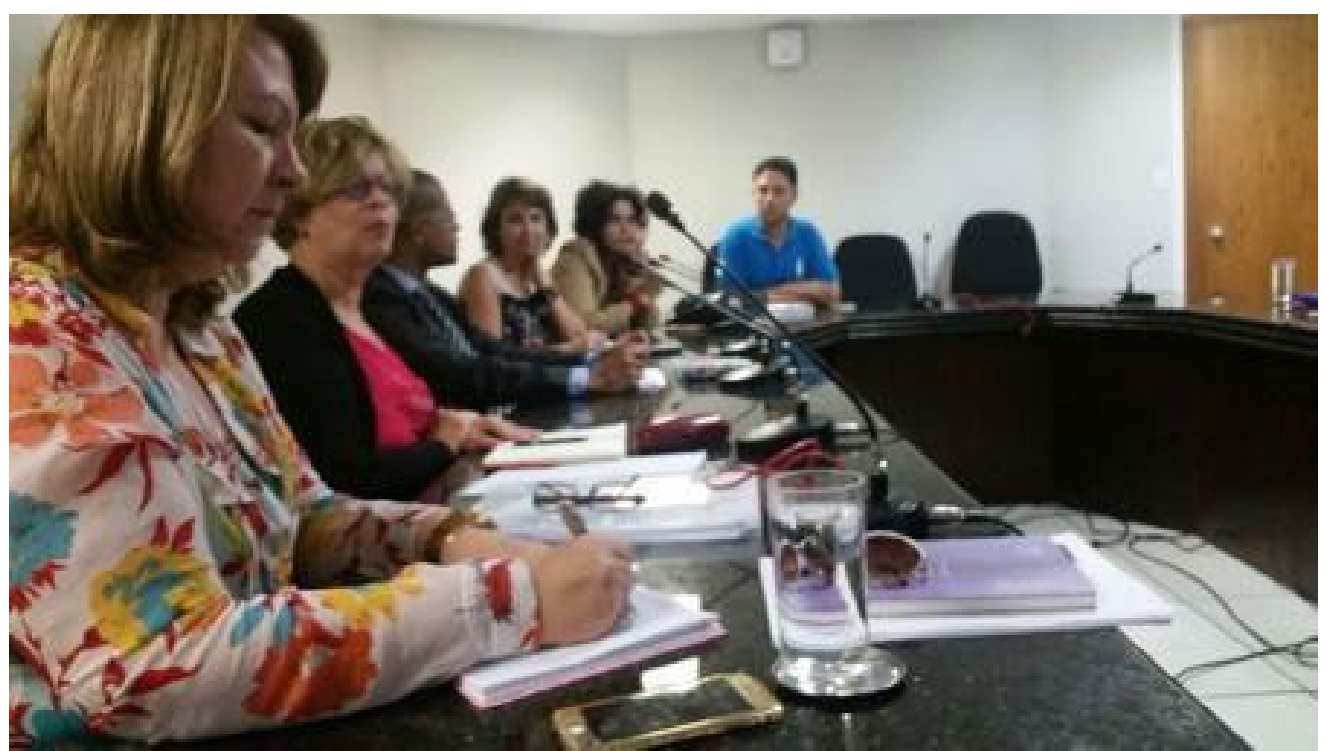

Imagem 3: Registro de reunião no Conselho Nacional de Educação. Fonte: Acervo da FAEB.

Os encontros posteriores foram importantes para a criação de uma agenda de debates e para o estreitamento do diálogo entre a FAEB, a ANPAP, a ANDA, a ABEM 
e a ABRACE, a exemplo do encontro convocado pelo MINC/SEFAC, que teve a finalidade do debate com as instituições federais de ensino superior para propor estratégias de fortalecimento no campo das artes e da cultura, no âmbito da atuação do Fórum Nacional de Formação e Inovação em Arte e Cultura e para definição de estratégias sobre a implementação da Lei no 13.278/2016, que inclui a obrigatoriedade das linguagens das Artes Visuais, da Dança, da Música e do Teatro no currículo da educação básica. O momento das discussões sobre a Lei colocou a FAEB no centro do debate e polemizou, no âmbito das políticas da cultura no país, a formação do professor de Arte, sua regulamentação e pertinência para mediar ações culturais, relacionada ao papel do artista na sociedade. Também foi possível reconhecer desafios no processo de implantação da Lei nos estados e instituições de ensino superior (IES), por incompreensão acerca do campo da Arte e suas especificidades.

Ainda em 2016, ano marcado pelo debate sobre a BNCC e pela alteração da Lei de Diretrizes e Bases da Educação Nacional (Lei n 9.394, de 20 de dezembro de 1996), no congresso anual da FAEB, XXVI CONFAEB, realizado na cidade de Boa Vista (RR), com a temática "Políticas Públicas e Ensino da Arte: processos educativos em Artes Visuais, Dança, Música e Teatro", aconteceu a mesa intitulada "Ensino de Arte na América Latina" com a professora Malvina Tuttman, professora titular da UNIRIO e conselheira do Conselho Nacional de Educação (CNE), que, em sua fala, debateu a importância das demandas das associações de pesquisa e ensino no campo da Arte para o compartilhamento de ações nas/para as políticas públicas educacionais, a exemplo da BNCC.

Um dos marcos para a produção de uma agenda conjunta das associações de pesquisa e ensino de arte deu-se pelo convite da professora Dulce Aquino para a composição de um Grupo de Trabalho no Simpósio Internacional Arte na Educação Básica, ocorrido em dezembro de 2017 na Universidade Federal da Bahia (UFBA). A FAEB foi representada pela Prof. a Dra. Ana Paula Abrahamian de Souza, a ANDA foi representada pelos professores Alexandre Molina e Eleonora Mota, a ABRACE foi representada pelos professores Marcílio Vieira e Robson Hadernchpek, a ANPAP foi representada pela Prof. a Dra. Maria Cristina da Rosa Fonseca da Silva e pela professora Carmem Moreira, e a ABEM foi representada pelos professores Luis Ricardo Queiroz e Marcus Medeiros. Estiveram presentes também a professora Kathia Godoy, a professora Sônia Regina Albano e o professor Claudio Cajaíba. Esse grupo de trabalho ganhou destaque para o fortalecimento das agendas de trabalho conjunto ao encaminhar que, em todos os congressos e encontros anuais ou bianuais das associações, seria aberto um espaço, via mesa-redonda ou grupo de trabalho, para o encontro e diálogo para a FAEB, a ANPAP, a ANDA, a ABEM e a ABRACE. 


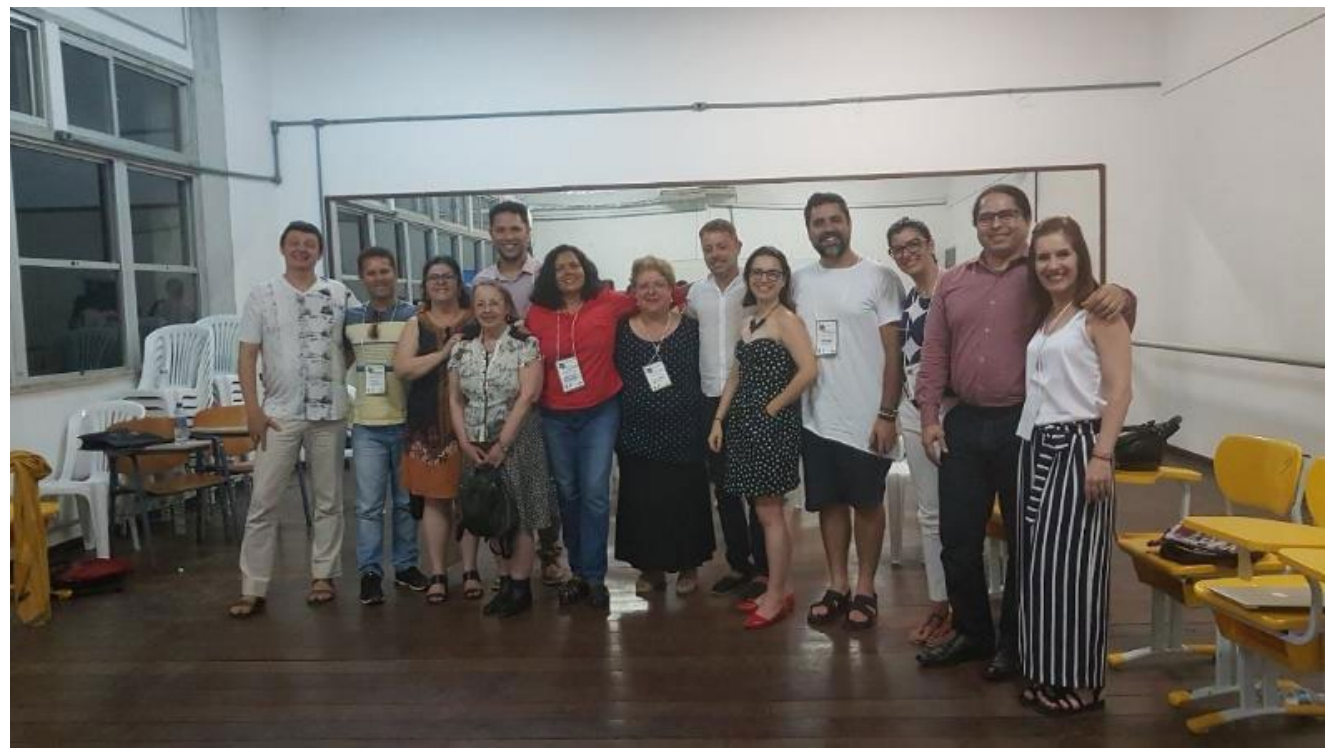

Imagem 4: Grupo de Trabalho das Associações no Simpósio Nacional Arte na Educação Básica. Fonte: Acervo da FAEB.

Fruto desse compromisso firmado, a FAEB promoveu em 2018 entre as instâncias representativas, durante o XXVIII Congresso da Federação de Arte/Educadores do Brasil, em Brasília, evento que, movido pelo mote deixado pela Prof. ${ }^{a}$ Dra. Isabela Frade, "Em águas de peixes grandes é necessário ser cardume", abriu caminho para a temática central do evento "CONFAEB 30 ANOS: ações políticas de/para enfrentamentos, resistências e recriações", por entender a importância e a urgência de, considerando as especificidades das Artes Visuais, da Dança, da Música e do Teatro, pensar as políticas no/para o campo da Arte/Educação na/para a coletividade em tempos de enfrentamentos políticos, de censuras à Arte e de tentativas de silenciamentos. Dessa vez, o encontro mobilizou as associações de ensino e de pesquisa em arte para ampliação dos debates acerca das políticas públicas educacionais para o ensino e para a pesquisa no campo da Arte no Brasil: ocorreu na mesa "Conexões entre as associações e as políticas educacionais", mediada pela Prof. a Dra. Ana Paula Abrahamian de Souza (UFRPE/PE), e contou com a participação da ANPAP, da ANDA, da $A B E M$ e da $A B R A C E$, representadas respectivamente pelo Prof. Dr. Marcílio de Sousa Vieira, pela Prof. ${ }^{a}$ Dra. Eleonora Santos Mota (UFPEL), pelo Prof. Dr. Robson Xavier (UFPB) e pelo Prof. Dr. Marcus Vinícius Pereira (UFJF).

Consideramos importante destacar que a mesa aconteceu poucos dias após o resultado das eleições e, movidos(as) pela imagem da tatuadora mineira Thereza Nardelli, que viralizou na época com a hashtag, a mesa também seguiu o mote "Ninguém solta a mão de ninguém". 


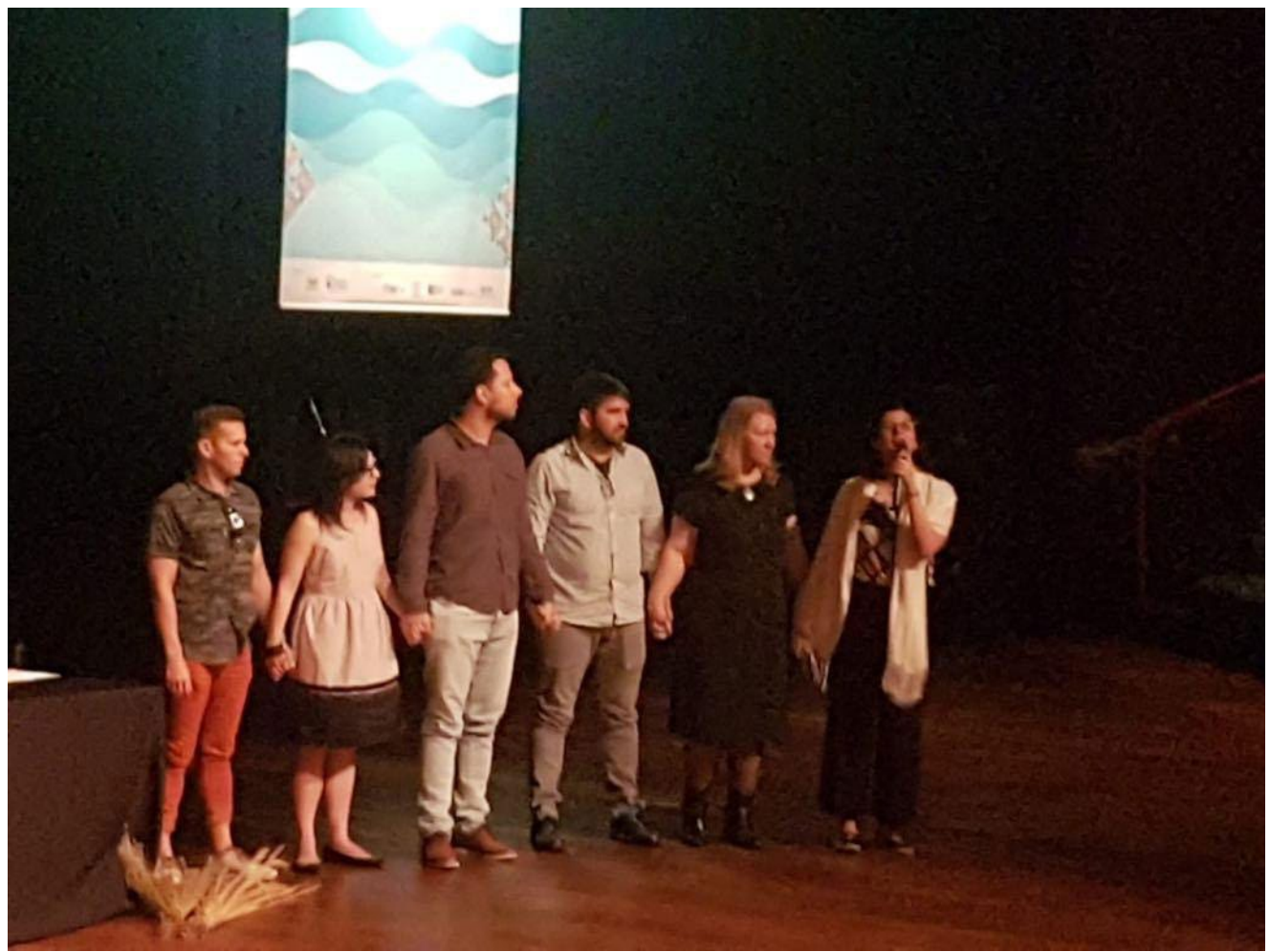

Imagem 5: Encerramento da Mesa das Associações - XXVIII CONFAEB, novembro de 2018, em Brasília. Fonte: Fabiana Vidal.

Finalizamos esse texto com o sentimento de que os últimos anos foram potentes para a promoção de agendas conjuntas entre as associações, que lutam em diferentes campos e que já entendem que pautas comuns entre os atores envolvidos, considerando as especificidades, precisam ser debatidas e fortalecidas num conjunto de ações sistematizadas e profissionalmente constituídas. Se avançamos em muitas questões, tais como ampliação do quadro de professores(as) com formação específica e com a qualificação na pós-graduação, por outro lado, continuamos enfrentando retrocessos em relação à conquista das questões de diversidade e gênero na educação, liberdades de manifestações artísticas etc. A luta continua... e ninguém soltará a mão de ninguém!

\section{Referências}

AZEVEDO, Fernando A. G. Multiculturalidade e um fenômeno da História da Arte/ Educação Especial. In: BARBOSA, Ana Mae (org.). Inquietações e mudanças no ensino da arte. São Paulo: Cortez, 1997.

AZEVEDO, Fernando A. G. Abordagem triangular: bússola para os navegantes destemidos dos mares da Arte/Educação. In: BARBOSA. Ana Mae; CUNHA, F. P. A Abordagem Triangular no Ensino das Artes e Culturas Visuais. São Paulo: Cortez, 2010. 
BARBOSA, Ana Mae. Tópicos Utópicos. Belo Horizonte: C/Arte, 1998.

BARBOSA, Ana Mae (org.). Inquietações e mudanças no ensino da arte. São Paulo: Cortez, 2002.

BARBOSA, Ana Mae. Tópicos Utópicos. 6. ed. Belo Horizonte: C/Arte, 1998.

BARBOSA, Ana Mae. Arte-Educação: leitura no subsolo. São Paulo: Cortez, 2005.

BARBOSA, Ana Mae. Políticas públicas para o ensino da Arte no Brasil: o perde e ganha das lutas. In: CONFAEB - POLÍTICAS PÚBLICAS E ENSINO DAS ARTES: FORMAÇÃO EM ARTES VISUAIS, DANÇA, MÚSICA E TEATRO, 25., 2015, Fortaleza. Anais [...]. Fortaleza, 2015.

BRASIL. Lei no 9.394, 20 de dezembro de 1996. Lei de Diretrizes e Bases da Educação Nacional. Estabelece as diretrizes e bases da educação nacional. Diário Oficial da União: Brasília, 23 dez. 1996. Disponível em: http://www.planalto.gov.br/ccivil_03/ LEIS/I9394.htm.

BRASIL. Ministério de Educação e Cultura. Lei no 13.278, de 2 de maio de 2016. Altera o $\S 6^{\circ}$ do art. 26 da Lei $n^{\circ} 9.394$, de 20 de dezembro de 1996, que fixa as diretrizes e bases da educação nacional, referente ao ensino da arte. Diário Oficial da União: Brasília, 3 maio 2016.

DELEUZE, Gilles; GUATARRI, Félix. Mil Platôs. Rio de Janeiro: Editora 34, 1995.

FAEB - FEDERAÇÃO DE ARTE/EDUCADORES DO BRASIL. Institucional. Paraná: FAEB, [s. I.]. Disponível em: https://faeb.com.br/institucional/.

FAEB - FEDERAÇÃO DE ARTE/EDUCADORES DO BRASIL. BNCC e FAEB: cartografias de uma luta. Boletim FAEB, Paraná, número especial, n. 1, 2016. Disponível em: http://faeb.com.br/admin/upload/files/-Boletim\%20Faeb_AU0303U00baltimo\%20 09\%2007\%202016.compressed.pdf.

FERNANDES, Sônia Regina. A luta pela não sujeição e a busca do empoderamento de professores da arte no Brasil do século XXI. In: SILVA, Ivete Souza, MENDES, Jerfferson; LUGE, Vinicius. Políticas públicas e o ensino da arte: processos educativos em artes visuais, dança, música e teatro. Boa Vista: Editora da UFRR, 2018.

NUNES, Ana Luiza Ruschel. Prefácio. In: SILVA, Ivete Souza, MENDES, Jerfferson; LUGE, Vinicius. Políticas públicas e o ensino da arte: processos educativos em artes visuais, dança, música e teatro. Boa Vista: Editora da UFRR, 2018. 
PEREIRA, Marcos Villela. A estética da professoralidade: um estudo crítico sobre a formação do professor. Santa Maria: Editora da UFSM, 2013.

PIMENTEL, Lúcia Gouvêa. Políticas públicas para o campo do ensino/aprendizagem das Artes Visuais na educação básica: contribuições da Associação Nacional de Pesquisadores em Artes Plásticas - ANPAP. In: CONFAEB ARTE-EDUCAÇÃO CONTEMPORÂNEA: METAMORFOSES E NARRATIVAS DO ENSINAR/APRENDER, 24. 2014, Ponta Grossa. Anais [...]. Ponta Grossa: EdUEPG, 2014.

RICHTER, Ivone Mendes. Multiculturalidade e interdisciplinaridade. In: BARBOSA, A. M. Inquietações e mudanças no ensino da arte. São Paulo: Cortez, 2002. 